\title{
VURGULU ELEKTRİK ALAN ÖN İŞLEMİ İLE DEREOTUNDAN FENOLIKLERİN EKSTRAKSIYYNU: DONDURUP ÇÖZÜNDÜRME, ISIL İŞLEM, MİKRODALGA ÖN İŞLEMLERİ VE SOLVENT EKSTRAKSIYYONU İLE KARŞILAŞTIRILMASI
}

\author{
Mustafa Fincan, Yasemin Çiftci* \\ Erciyes Üniversitesi, Mühendislik Fakültesi, Gıda Mühendisliği Bölümü, Kayseri, Türkiye
}

Geliş / Received: 28.05.2021; Kabul / Accepted: 30.09.2021; Online bask1 / Published online: 18.10.2021

Fincan, M., Çiftci, Y.. (2021). Vurgulu elektrik alan ön işlemi ile dereotundan fenoliklerin ekstraksiyonu: Dondurup çözündürme, 1 sıl işlem, mikrodalga ön işlemleri ve solvent ekstraksiyonu ile karşılaştırılması. GIDA (2021) 46 (6) 1343-1357 doi: 10.15237/gida.GD21092.

Fincan, M., Ciftci, Y.. (2021). Extraction of phenolics from dill leaf with pulsed electric field pretreatment: comparison with freeze thaw, heat treatment, microwave pretreatments and solvent extraction. GIDA (2021) 46 (6) 1343-1357 doi: 10.15237/gida.GD21092.

\section{ÖZ}

Bu çalısmada 3-4 kV/cm aralığındaki vurgulu elektrik alan uygulamasının dereotu dokusunu bozma düzeyleri elektriksel iletkenlik bazlı bir parçalanma indeksi ile tahmin edilip, en yüksek bozunumu sağlayan şartlarda fenoliklerin ekstrakte edilebilirliği katı-sıvı ekstraksiyon sisteminde incelenmiștir. Ekstraksiyon sonunda, toplam fenolik içerik (TFI), antioksidan kapasite (AK) ve antiradikal aktivite (AA) değerleri ölçülüp, diğer ön işlemlerinki (dondurma-çözme, mikrodalga, solvent işlemi ve 1sıl işlem) ile karşılaştırılmıştır. En yüksek

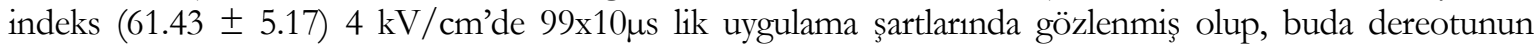
parçalanma direncinin çalışmada kıyaslanan parankim dokularından ve yenilebilir yapraklardan yüksek olduğuna işaret etmiştir. Vurgulu elektrik alan destekli ekstraksiyonun TFI ve AK değerleri dondurupçözündürme ön işleminden yaklaşık \%35 oranında düşük bulunurken, ssıl işlem içeren (mikrodalga, solvent işlemi ve 1 sll işlem) yöntemlerden ortalamada $\% 68$ oranında düşük tespit edilmiştir. Vurgulu elektrik alan önişleminde ekstraksiyon veriminin, doku parçalanma düzeyinden ve fenoliklerin polifenol oksidaz (PPO) tarafindan bozulmasından etkilendiği șeklinde yorumlanmıştır.

Anahtar kelimeler: vurgulu elektrik alan, fenolik bileşikler, kat1-sıv1 ekstraksiyon, dereotu

\section{EXTRACTION OF PHENOLICS FROM DILL LEAF WITH PULSED ELECTRIC FIELD PRETREATMENT: COMPARISON WITH FREEZE THAW, HEAT TREATMENT, MICROWAVE PRETREATMENTS AND SOLVENT EXTRACTION}

\begin{abstract}
In this study, disintegration of dill leaf in response to pulsed electric field pretreatment of $3-4 \mathrm{kV} / \mathrm{cm}$ was estimated using an electrical conductivity based-index, and extractability of phenolics at the highest index was studied in a solid-liquid extraction. Total phenolic content (TPC), antioxidant capacity (AC), and antiradical activity (AA) of the extraction were compared with other pretreatments
\end{abstract}

\footnotetext{
*Yazışmalardan sorumlu yazar / Corresponding author

17): yasemenciftcii@gmail.com

(ग): (+90) 5443920369

国: (+90) 3524375784
}

Mustafa Fincan; ORCID no: 0000-0002-9394-6449

Yasemin Çiftci; ORCID no: 0000-0001-9934-0723 
(freeze-thaw, microwave, heat and solvent extraction). The highest index $(61.43 \pm 5.17)$ was obtained at $99 \times 10 \mu$ s of $4 \mathrm{kV} / \mathrm{cm}$, implying a higher disintegration resistance than the parenchyma tissues and edible leaves compared in the study. TPC and AC of the extraction were found around $35 \%$ less than those of the freeze-thaw while about $68 \%$ lower than the microwave, heat treatment and solvent extraction. The yield of pulsed electric field extraction has been interpreted as affected by the degree of disintegration and degradation of phenolics by polyphenol oxidase (PPO).

Keywords: Pulsed electric field, phenolic compounds, solid-liquid extraction, dill

\section{GİRİ̧̧}

Taze bitkilerden fenolikler gibi hücre içi maddelerin ekstrakte edilmesinde hücre zarlarının sağlamlı̆̆1, ekstraksiyon verimini etkileyen önemli faktörlerden biridir. Fenolik maddeler bitkisel hücrede koful içerisinde zarlarla (tonoplast ve plasmalemma) çevrelenmiş olarak bulunduğundan, diş bir ortama geçişi sağlam hücre zarları tarafindan engellenmektedir. Fenolik maddelerin etkin bir şekilde ekstraksiyonunun sağlanması için öncelikle hücre zarı direncinin aşılması veya bozundurulması gerekmektedir (Handa vd., 2008). Hücre zarı bozundurma işlemi, ekstraksiyon çeşidine bağlı olarak ekstraksiyon öncesi veya esnasinda 1si uygulamas1, kurutma ve ögütme gibi çeşitli yöntemler uygulamak suretiyle gerçekleştirilmektedir. Kat1-sıv1 ekstraksiyon sisteminde hücre zarlarının sağlamlı̆̆ı, kullanılan solvent (çözücü) çeşidinin polaritesinden de etkilenmektedir. Bir kısım yağ çözücü aseton gibi apolar solventler, hücre zarına ulaştığında lipid açısından zengin olan hücre zarını çözerek bozundurma etkisine sahipken, su bazlı ekstraksiyonda bu etki sınırlı olup, hücre zarları önemli oranda sağlam kalmaktadır (Xu vd., 2017). $\mathrm{Bu}$ nedenle ön işlemler ile hücre zarlarının bozundurulması özellikle su bazlı ekstraksiyonda daha kritik bir öneme sahip olmaktadır (Dai ve Mumper, 2010). Gerek su bazlı gerek solvent bazlı olsun kat1-siv1 ekstrasiyonda, ekstraksiyon verimini artırmaya yönelik birçok geleneksel ve yeni gelişen yöntemlerin etkisi yaygın araştırma konularındandır. $\mathrm{Bu}$ yöntemlerin her birinin avantaj ve dezavantajları vardır. Örneğin, fenolik maddelerin apolar solventlerde çözünürlüğü daha fazla olduğu için solvent bazlı ekstraksiyonda verim genellikle daha yüksek olurken, solvent maliyeti ve kalıntısı bir dezavantaj olarak görülmektedir. Ayrıca, 1sıl ön işlemin bazı bitkilerde 1sıya duyarlı fenolik maddelerin bozunumuna yol açtı̆̆ bitkilerde ise fenolik madde veya antioksidan aktivite değerlerinin artırıc1 etkisi gösterilmiştir (Fanasca vd., 2009; Chipurura vd., 2010; Chumyam vd., 2013; Maghsoudlou vd., 2019).

Son yıllarda ortaya çıan, vurgulu elektrik alan (PEF) uygulaması, önemli bir 1sı artışına neden olmadan hücre zarlarında gözenek oluşumuna yol açan, düşük enerji maliyetli bir doku parçalama tekniği olarak kabul edilmiştir. Bitki dokusu üzerine yapılan önceki birçok çalışmada PEF'in hücre içi bileşiklerin kütle transferini ekstraksiyon ve kurutma gibi proseslerde kolaylaştırdığ ve verimi artırdığ1 rapor edilmiştir (Fanasca vd., 2009; Barba vd., 2012; Vallverdú-Queralt vd., 2012). Bu çalışmaların birçoğunda incelenen bitki doku çeşidi, meyve et dokusu veya parankima dokulardır. Bununla birlikte, literatürde PEF'in yapraks1 (tıbbi, aromotik, yenilebilir) bitkilerde etkilerini inceleyen çalışmalar sınırlı sayıdadır. Çay yapraklarında yapılan bir çalışmada, PEF ön işlemi uygulanan yapraklardan fenolik maddelerin kat1siv1 ekstraksiyon sistemi ile elde edilmesinde, en yüksek ekstraksiyon verimi için PEF şartlar1 1.25 $\mathrm{kV} / \mathrm{cm}$ elektrik alan kuvveti 99 vurgu olarak rapor edilmiştir (Liu vd., 2019). Benzer bir çalışmada, taze nane yapraklarından fenolik maddelerin ekstrakte edilebilirliği PEF ön işlemi ile artmış, optimum hücre parçalanması için $3 \mathrm{kV} / \mathrm{cm}$ elektrik alan kuvvetinde 99 vurgu kullanilması önerilmiştir (Fincan, 2015). Başka bir çalışmada, Stevia rebaudiana yapraklarından fenolik madde ekstraksiyonu mikrodalga, ultrason, vurgulu elektrik alan ve yüksek voltajlı elektrik deşarj ön işlemleri arasında en yüksek verim PEF ile muamele edilmiş örneklerde $(20 \mathrm{kV} / \mathrm{cm}, 200$ vurgu) rapor edilmiştir (Carbonell-Capella vd., 2017).

Dereotu (Anethum graveolens L.) fenolik, flavonoid ve tanen bakımından zengin ve morfolojik olarak yapraksı bitkilerden farklı diğer aromatik, yenilebilir bitkilerden biridir (Fanasca vd., 2009; 
Niya vd., 2016). Dereotu, fenolik asitler (klorojenik asit, vanilik asit, siringik asit, kumarik asit, ferulik asit, benzoik asit), flavonol (kamferol, kuersetin ve rutin), flavon (apigenin, lutealin) flavanon (naringenin) gibi fenolik bileşikler içermektedir (Świeca ve Gawlik-Dziki, 2008; Shyu vd., 2009). Yapılan bir çalışmada, dereotu bitkisinin polifenol, flavonoid içeriği ve antioksidan aktivitesini belirlemek için, solvent ekstraksiyon metodu kullanılmış, hazırlanan etanol ve sulu yaprak ekstrelerinin toplam fenolik madde içerikleri sırasıyla $69.76 \pm 1.57$ ve $47.71 \pm$ $1.44 \mathrm{mg}$ GAE/g kuru ekstrakt olarak tespit edilmiştir. Su ve etanol ekstraktları kıyaslandığında ise etanol ekstraktının daha iyi antioksidan ve antiradikal aktivite sergilediği görülmüştür (Nguyen vd., 2020). Dereotundan fenolik maddelerin ekstraksiyonu için solvent, ultrason ve mikrodalga metotlarının kullanıldığı rapor edilmiştir (Shyu vd., 2009; Isbilir ve Sagiroglu, 2011; Pandey vd., 2013; Vallverdú-Queralt vd., 2015; Niya vd., 2016; Paven vd., 2018).

Bu çalışmada dereotu dokusunu PEF ön işlemi ile parçalamanın fenolik ekstraksiyonunu nasil etkilediği, su bazlı ve solvent bazlı katı-sıv1 ekstraksiyon sisteminde araştırılmıştır. Öncesinde, farklı şiddetteki PEF uygulamalarının ortaya çıkardığ1 doku parçalanma düzeyi elektriksel iletkenlik bazlı bir doku parçalama indeksi ile tahmin edilip, sonrasında dokuları PEF ile en yüksek oranda parçalanan örnekler katı-sıv1 ekstraksiyon işlemine maruz bırakılmıştır. PEF’in etkisi ekstraktlarda toplam fenolik içerik (TFi), antioksidan kapasite (AK) ve antiradikal aktivite (AA) analizleri ile değerlendirilip, kontrol ve diğer ön işlem gruplar1 (dondurup-çözündürme, mikrodalga, solvent işlemi ve 1 ssl işlem) ile karşılaştırılmıştır.

\section{MATERYAL ve YÖNTEM \\ Örnek hazırlama}

Taze dereotu (Anethum graveolens, Apiaceae), türden kaynaklanan değişimleri önlemek amaciyla Kayseri'de sürekli aynı marketlerden temin edilerek çalışmalarda kullanılmıştır. Temin sonrası materyaller, çoğunlukla hemen deneye alınmıs, istisnai hallerde buzdolabinda $+4{ }^{\circ} \mathrm{C}$ 'de plastik torbalar içerisinde en fazla 4 gün muhafaza edilmiştir. 200 mg örnek yaprak kısmından kesildikten sonra, distile su ile yıkanıp kalan su peçete kâğıt ile uzaklaştırılmıştır. Daha sonra örnek, uygulama odacığına yerleştirilip ve üzerine $800 \mu \mathrm{l}$ izotonik mannitol (0.33 M) çözeltisi (D(-) Mannitol, Merck) ilave edilerek, uygulamalar için hazır hale getirilmiştir. Mannitol, metabolik olarak inert ve suda çözündüğunde ortamın elektriksel iletkenliğinde önemli bir artışa yol açmadığından, deneylerde ozmotik etkileri en aza indirmek amacına yönelik izotonik olarak hazırlanıp kullanılmıştır (Gaidamauskas vd., 2005).

\section{Deneysel düzenek}

PEF ön işlemi ve empedans ölçümü Şekil 1a'da verilen entegre sistem kullanılarak gerçekleştirilmiştir. Uygulama odacığı iki çift paslanmaz çelikten oluşan paralel plakalardan imal edilmiş (Şekil 1b), bir çifti PEF uygulaması, diğer çifti ise empedans ölçümü için kullanılmıştır. Uygulama odacığının mutlak empedans 100 kHz'de ve $20 \mathrm{mV}$ (rms)'lik sabit test voltajinda bir LCR metre (Hioki 3532-50, Japan) ve probu (Hioki 4-terminal probe 9140) kullanılarak ölçülmüsstür. Veriler LCR metreye bağlı bir arayüz (Hioki RS-233C, 9593-01, Japan) kullanarak bilgisayara aktarılıp, bilgisayar yazılımı (Hioki LCR version 4.03.E, Japan) ile kaydedilmiştir. Ölçümlerden önce kablo ve elektrotlardan kaynaklanan empedans değerleri, LCR metredeki program yardımıyla ölçümlerden çıkarılmışır (açık ve kısa kompanzasyon).

\section{PEF uygulaması ve empedans ölçümü}

Uygulama odacı̆̆ına örnekler yerleştirilip, empedans ölçüm elektrotları arasından LCR metreye bağlantı sağlandiktan sonra, empedans verileri yaklaşık 10 dakika boyunca ölçülerek bilgisayara kaydedilmiştir. Sonrasında, LCR metre bağlantısı kesilip, PEF uygulama elektrotları bağlantısından PEF jeneratörüne (ECM 830, Harvard apparatus, USA) bağlanip PEF uygulanmıştır. PEF protokolünde, 3 ve $4 \mathrm{kV} / \mathrm{cm}$ elektrik alan şiddetinde $100 \mathrm{~ms}$ aralıklı $10 \mu \mathrm{s}^{\prime}$ lik karesel monopolar vurgulardan 99 adet uygulanmıştır. PEF sonrası uygulama odacığ1 tekrar LCR metreye bağlandiktan sonra, empedans verileri 50 dakika boyunca her dakika ölçülüp, bilgisayara kaydedilmiştir. Hiçbir işlem 
görmemiş ve dondurulup-çözündürülmüş örneklerin empedans ölçümleri de benzer şekilde yapılmıştır. Dondurup-çözündürme işlemi bitkisel dokuları \%100'e yakın parçalamayı sağlayan yaygin yöntemlerden biridir (Angersbach vd., 2002). Dondurulup-çözündürülmüş örnekler, önce izotonik mannitol çözeltisi içinde $-20^{\circ} \mathrm{C}$ 'de
2 hafta boyunca bekletildikten sonra, çözündürülerek oda sıcaklı̆̆ına getirilip hazırlanarak ölçümlerde kullanılmıştır. Dondurup-çözündürme işleminde mannitol çözeltisi diğer örneklerden farklılık oluşturmaması için kullanılmıştır.

(a)

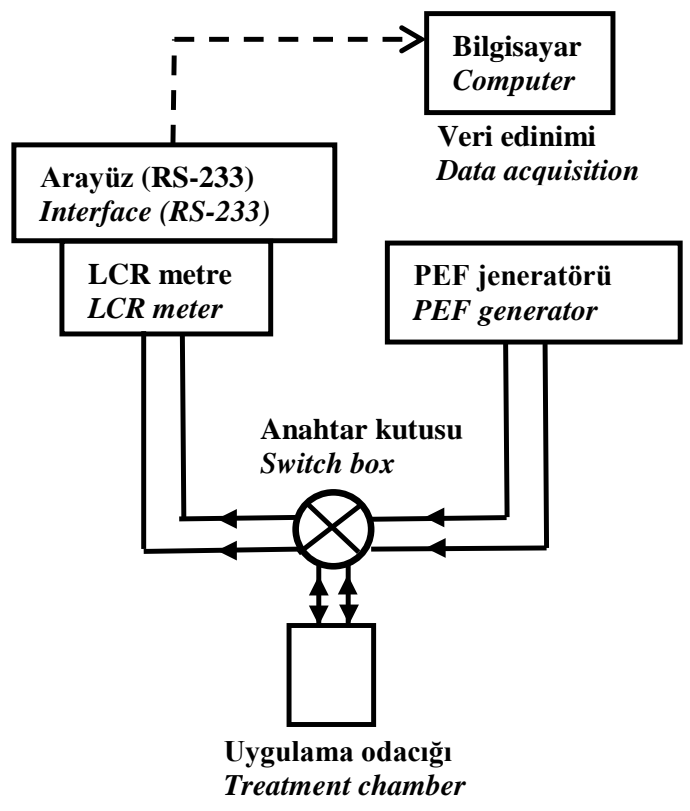

(b)

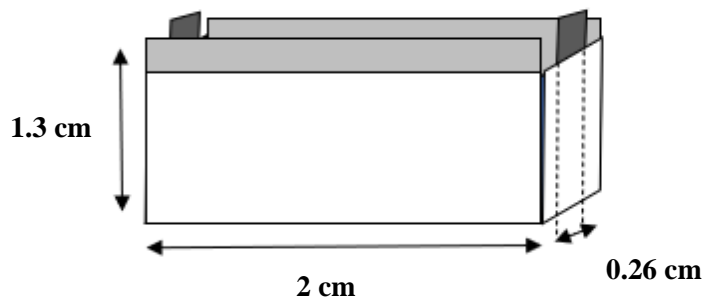

\section{$\square$ :Empedans ölçüm elektrotları Impedance measurement electrodes \\ :PEF uygulama elektrotları PEF application electrodes \\ :Yalıtım Isolation}

Şekil 1. (a) PEF uygulaması ve empedans ölçümü için deneysel kurulum (b) Uygulama odaciğının şematik resmi

Figure 1. (a) Experimental set-up for PEF application and impedance measurment (b) Schematic picture of treatment chamber

Doku parçalanma indeksinin (DPİ) tahmini Ölçülen empedans değerlerinden, doku + mannitol çözeltisinin elektriksel iletkenliği $(\sigma$, Simens $/ \mathrm{m}$ ), aşağıdaki formülden hesap edilmiştir (Barsotti vd., 1999): $\sigma=\ell /(Z \times A)$

(Denklem 1)

$\ell=$ ölçüm elektrotları arasındaki mesafe (m), $\mathrm{Z}=$ doku + mannitol çözeltisinin empedansı (ohm, $\Omega), A=$ ölçüm elektrotunun yüzey alanı $\left(\mathrm{m}^{2}\right)$ 
PEF işlemine maruz birakılan örneklerin parçalanma düzeyini belirlemek amacıyla, doku parçalanma indeksi (DPI) aşağıdaki formülden hesap edilmiştir (Bazhal, 2003).

DPI $=\left[\left(\sigma-\sigma_{s}\right) /\left(\sigma_{d c}-\sigma_{s}\right)\right] \times 100 \quad($ Denklem 2$)$

$\sigma=$ Farklı PEF işlemlerine maruz bırakılan dokunun 50 dakika sonundaki elektriksel iletkenliği (Simens $/ \mathrm{m}$ ), $\sigma_{\mathrm{s}}=$ sağlam (hiçbir işlem görmemiş) dokunun 50 dakika sonundaki elektriksel iletkenliği (Simens $/ \mathrm{m}), \quad \sigma_{\mathrm{dc}}=$ dondurulup-çözündürülmüş dokunun elektriksel iletkenliği (Simens/m)

Buna göre yukarıdaki formül hiçbir işlem görmemiş (sağlam) doku için DPİ $\approx 0$ değerini verirken, dondurulup-çözündürülmüss doku için DPI $\approx 100$ değerini vermektedir (De Vito vd., 2008).

\section{Kat1-siv1 faz ekstraksiyonu}

Bütüne yakın doku parçalanmasını sağlayacak şiddette, aşağıda belirtilen ön işlemler ile muamele edilen örnekler, kat1-sıv1 ekstraksiyon işlemine maruz birakılmıştır (Zhang ve Willison, 1992; Ade-Omowaye vd., 2000; Pan vd., 2003; Roy vd., 2007). Ekstraksiyon için, $1 \mathrm{~g}$ ön işlem görmüş doku örneği üzerine $20 \mathrm{~mL} 0.33 \mathrm{M}$ mannitol çözeltisi ilave edildikten sonra, erlenmeyer içerisine aktarılarak dakikada 180 devirde çalışan rotasyon çalkalayıcıda (Shel Lab SI6 Floor model incubator, Amerika) 90 dakika boyunca karıştırılmıştır. Ekstraksiyon sicaklı̆̆1 solvent işlemi için $70^{\circ} \mathrm{C}^{\prime}$ de iken diğer ön işlemler için 20 ${ }^{\circ} \mathrm{C}$ 'de gerçekleştirilmiştir. Ekstraksiyon sonunda elde edilen ekstraktlar, filtre (Qualitative filter paper, 101 fast, Xinxing, Çin) edilerek, posa kısmı ayrilıp, siv1 k1smı (ekstrakt) fenolik maddelerin analizinde kullanılmıştır (Fincan, 2015).

\section{Önişlemler}

PEF ön işlemi: Ade-Omowaye vd. (2000) tarafindan rapor edilen prosedürlere uygun olarak gerçekleştirilmiştir. Empedans ve dondurulupçözündürme deneyleri referans alınarak en yüksek parçalanma oranın sağlandığ $4.5 \mathrm{kV} / \mathrm{cm}$ alan şiddeti 99 vurgu şartları uygulanmıştır. Vurgu genişliği $10 \mu$ s ve vurgular arası mesafe 100 ms olarak uygulamalarda sabit tutulmuştur.
Mikrodalga ön işlemi: Pan vd. (2003)'e ait yönteme göre gerçekleştirilmiştir. Doku örneği 800 W güçteki mikrodalgada (Kenwood MW796, Japonya) 4 kez 30 saniye boyunca işleme maruz bırakılmıştır. Her bir 30 saniye sonrasinda örnekler 20 saniye çeşme suyu altında soğutularak, 1sınmadan kaynaklanan buharlaşma olmamasına özen gösterilmiştir.

Isıl ön işlemi: Roy vd. (2007) tarafindan rapor edilen prosedürlere uygun olarak gerçekleştirilmiştir. Doku örneği $80{ }^{\circ} \mathrm{C}$ 'de 150 dakika boyunca tutulmuş, sonrasında çeşme suyu altında soğutulmuştur.

Dondurup-çözündürme yöntemi: Zhang ve Willison (1992)'a ait yönteme göre gerçekleştirilmiştir. Yaklaşık 1/8 (g/mL) katı sıvı oranındaki örnekler $-20{ }^{\circ} \mathrm{C}$ 'deki dondurucuda en az 1-2 hafta tutulmuş, daha sonra örnekler çözündürülerek katı sıv1 oranı 1/20'ye ayarlanmışır.

Solvent ekstraksiyonu: Kaufmann ve Christen (2002) tarafindan rapor edilen prosedürlere uygun olarak gerçekleştirilmiştir. Etanol çözeltisi (20:80, su / etanol) hazırlanarak $70{ }^{\circ} C^{\prime}$ ye 1 sitılmış, bu çözeltinin $20 \mathrm{~mL}$ 'sine $1 \mathrm{~g}$ örnek ilave edilerek ekstraksiyon için hazır hale getirilmiştir.

Kontrol: Örneklere hiçbir doku parçalama işlemi uygulanmadan ekstraksiyon için hazır hale getirilmiştir.

\section{Toplam fenolik madde tayini}

Ekstrakt vortekslenerek (Vortex MX-S, Dragonlab, Çin) $100 \mu \mathrm{l}$ supernatant alınmıs, ardindan $100 \mu \mathrm{l}$ etanol (\%95) ilave edilerek, üzerine $3 \mathrm{~mL}$ Folin ayırac1 $(\% 10 \mathrm{~mL} / \mathrm{mL})$ eklenmiştir. Çözelti vortekslenerek 5 dakika bekletme sonrasında üzerine $3 \mathrm{~mL}$ sodyum karbonat $(\% 7 \mathrm{~g} / \mathrm{mL})$ çözeltisi ilave edilmiş, tekrar vortekslenerek oda sicaklığında 1 saat beklemeye bırakılmıştır. Oluşan mavi renkli çözeltinin absorbans1, supernatant yerine $100 \mu \mathrm{l}$ mannitol (0.33 M) çözeltisi kullanılan kontrole karş1 spektrofotometrede (Shimadzu UV-1700 spectrophotometer, Japonya) $760 \quad$ nm'de ölçülmüştür. Toplam fenolik madde miktarı, gallik 
asit cinsinden $\mathrm{mg} / \mathrm{mL}$ olarak ifade edilmiştir. Gallik asit standart eğrisi (Şekil 2), 50-250 mg/L konstantrasyon aralığında hazırlanan gallik asit standart çözeltilerinin her birinden $100 \mu \mathrm{l}$ alınarak, supernatant yerine kullanılmış ve okunan absorbans değerleri ile $y=2.2233 x+0.0022\left(R^{2}\right.$
$=0.9999)$ oluşturulmuştur. $1 \mathrm{~g}$ taze örnekten ekstrakte edilen toplam fenolik madde, grafikten bulunan konsantrasyonun toplam ekstrakt hacmi ile çarpımından hesap edilmiş ve $m g$ gallik asit eşdeğeri/g taze doku olarak ifade edilmiştir (Nagy vd., 2014).

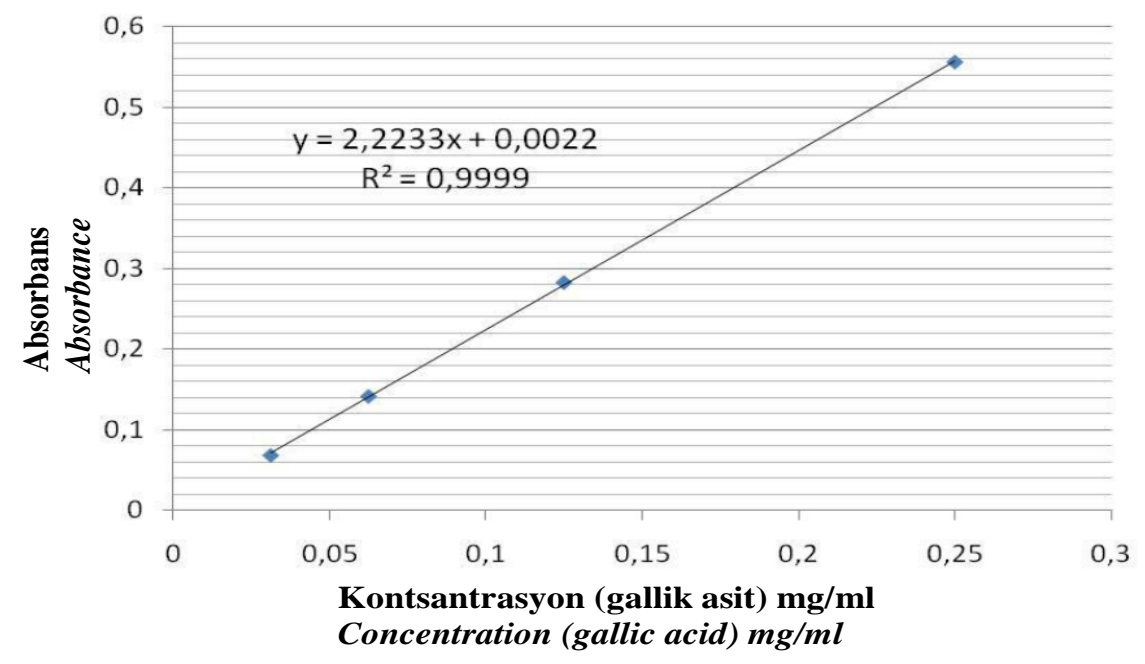

Şekil 2. Gallik asit çözeltisinin standart eğrisi

Figure 2. Standard curve of gallic acid solution

\section{Antioksidan kapasite tayini}

Ekstrakt vortekslenerek (Vortex MX-S, Dragonlab, Çin) $0.25 \mathrm{~mL}$ supernatant alınmış, üzerine $1 \mathrm{~mL}$ metanol (\%99) ve $2 \mathrm{~mL}$ karışım çözeltisi ( $0.6 \mathrm{M}$ sülfürik asit, $28 \mathrm{mM}$ trisodyum fosfat, $4 \mathrm{mM}$ amonyum molybdat) ilave edilerek vortekslenmiştir. Çözelti $95{ }^{\circ} \mathrm{C}$ 'de 90 dakika boyunca su banyosunda tutulmuştur. Daha sonra oda sicakliğına getirilen örneklerin absorbans1, supernatant yerine mannitol $(0.33 \mathrm{M})$ çözeltisi kullanılan kontrole karşı spektrofotometrede 695 nm'de ölçülmüştür. Toplam antioksidan kapasite, askorbik asit cinsinden $\mathrm{mg} / \mathrm{mL}$ olarak ifade edilmiştir. Askorbik asit standart eğrisi (Şekil 3), $55-250 \mathrm{mg} / \mathrm{L}$ konsantrasyon aralığında hazırlanan askorbik asit standart çözeltilerinin her birinden $0.25 \mathrm{~mL}$ alınarak supernatant yerine kullanılmış ve okunan absorbans değerleri ile $\mathrm{y}=2.6125 \mathrm{x}-$ $0.0572\left(\mathrm{R}^{2}=0.9998\right)$ oluşturulmuştur. $1 \mathrm{~g}$ taze örnekten ekstrakte olan toplam antioksidan kapasite, grafikten bulunan konsantrasyonun toplam ekstrakt hacmi ile çarpımından hesap edilmiş ve mg askorbik asit eşdeğeri/g taze doku olarak ifade edilmiştir (Cao vd., 2011)

\section{Antiradikal aktivite tayini}

Ekstrakt vortekslenerek (Vortex MX-S, Dragonlab, Çin) $40 \mu \mathrm{l}$ supernatant alınmıs, üzerine $3 \mathrm{~mL}$ metanol ile hazırlanmış $\mathrm{DPPH}$ çözeltisi (4 mg/ $100 \mathrm{~mL}$ ) ilave edilerek vortekslenmiştir. Karışım karanlıkta oda sıcaklı̆̆ında 60 dakika boyunca bekletilmiş ve çözeltinin absorbansı $517 \quad$ nm'de spektrofotometrede ölçülmüştür. Absorbans ölçümlerinde metanol kullanılarak absorbans sıfirlanmış, kontrol ölçümünde supernatant yerine mannitol (0.33 M) kullanılmıştır (SánchezMoreno vd, 1998; Kunyanga vd., 2012).

Antiradikal aktivite \% inhibisyon olarak aşağıdaki formülden hesap edilmiştir:

\%İnhibisyon $=[(K-0 ̈) / K] \times 100 \quad($ Denklem 3$)$

$\mathrm{K}=$ Kontrol, mannitol kullanıldığındaki absorbans değeri,

Ö = Örnek, örnek kullanıldığındaki absorbans değeri 


\section{Verilerin istatistiksel analizi}

Çalışmada her bir deney için beş tekerrürlü empedans sonuçları ve beş tekerrürlü ve üç paralel fenolik madde sonuçları Minitab (Minitab inc.,
Minitab for Windows, release 12.2, Amerika) istatistiksel program1 kullanılarak, varyans (ANOVA) analizi ile değerlendirilmiştir.

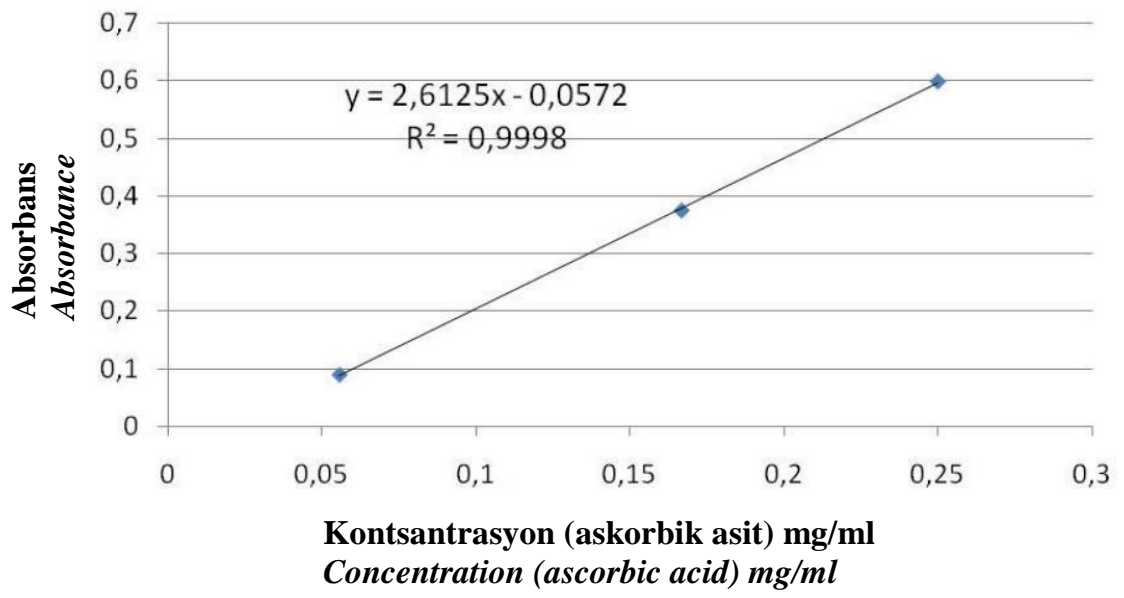

Şekil 3. Askorbik asit çözeltisinin standart eğrisi

Figure 3. Standard curve of ascorbic acid solution

\section{BULGULAR ve TARTIŞMA}

PEF'in hücre içi iyonların salınımı üzerine etkisi

Şekil 4'de, PEF uygulanmış, dondurulupçözündürülmüş ve işlem görmemiş örneklerden hücre içi iyonların salınma kinetiği verilmiştir. İşlem görmemiş örneklerin elektriksel iletkenliği 60 dakika boyunca sabite yakın seyrederken (Şekil 4a), 10. dakikada uygulanan PEF sonras1, elektriksel iletkenlikte gözlenen artıs hücre zarının parçalanmış olduğuna, bu sebepten iyonların dış ortama salınmaya başladığına işaret etmektedir (Şekil 4b ve c). \%100'e yakın doku parçalamayı sağlayan dondurup-çözündürme işleminde ise, başlangıçta bütün iyonlar ortama salındığı için sonraki zamanlarda artış gözlenmemektedir (Şekil 4a). Bundan başka, PEF uygulanmış örneklerden iyon salınım hızının nispeten düşük bir hızda gerçekleşmesi dikkat çekici olmuştur. Zira, önceki bir çalışmada soğan epidermisi PEF yollu parçalandığında iyon salınım hızının daha yüksek olduğu gözlenmiştir (Fincan ve Dejmek, 2002). PEF uygulanmış örneklerde gözlenen bu düşük iyon salınım hızının, hücre zarındaki gözeneklerin küçüklüğü ve mumsu kütikula tabakasının direnci ile ilişkili olabileceği düşünülmektedir. Özellikle hücre zarı üzerinde çok küçük gözenekler oluştuğunda iyon salınımı hızı yavaşlamakta ve salınım uzun sürmektedir (Şekil $4 \mathrm{a}$ ve b'de 60 dakika sonunda bile devam etmektedir). Nitekim önceki çalışmalarda vurgu genişliği ile gözenek çap1 ve sayısı arasında ilişki olduğu, örneğin, vurgu genişliğinin mikrosaniyeden milisaniyeye çıkarıldığında gözenek çapının da büyüyeceği belirtilmiştir (Saulis, 2010).

Ayrıca, PEF şiddetinin $3 \mathrm{kV} / \mathrm{cm}$ 'den $4 \mathrm{kV} / \mathrm{cm}$ 'ye çıkarılması da, iyon salınım kinetiği açısından belirgin bir fark oluşturmamıştır.

\section{PEF'in doku parçalanma seviyesi üzerine etkisi}

Şekil 5'te dereotuna iki farklı şiddete PEF uygulaması ( $3 \mathrm{kV} / \mathrm{cm}$ 'de $99 x 10 \mu$ s ve $4 \mathrm{kV} / \mathrm{cm}$ 'de 99x10 $\mu \mathrm{s})$ sonrasinda gelişen doku parçalanma indeksi (DPI) gösterilmiştir. Bu şartlarda DPİ değerleri sirasiyla $53.73 \pm 15.64$ ve $61.43 \pm 5.17$ olarak hesaplanmıştır. Uygulanan PEF şiddetine karş1 gelişen DPİ değerinin, çoğu parankim ve geniş yüzeye sahip yapraksı dokulardan daha düşük olduğu tespit edilmiştir (Donsì vd., 2010). Diğer bir deyişle, sonuçlar dereotu dokusunun PEF ile parçalanmaya dirençli olduğunu göstermektedir. Çünkü, meyve ve sebzelerin et kısmını oluşturan parankima hücrelerine sahip 
dokularda bütüne yakın parçalamayı sağlayan PEF uygulamas1 1-1.5 kV/cm şiddetindedir (SolivaFortuny vd., 2009). Bu nedenle dereotu dokusunda bütüne yakın parçalanma sağlamak için $4 \mathrm{kV} / \mathrm{cm}$ 'den daha yüksek PEF şiddetleri uygulanması gerekmektedir. Ayrica, benzer bir çalışmada, taze nane yaprağı dokularına 3 $\mathrm{kV} / \mathrm{cm}$ 'de 99x10 $\mathrm{s}^{\prime}$ lik PEF uygulamasinda DPI değeri \%90'a yakın bulunmuştur (Fincan, 2015). Dereotunun PEF ile parçalanmaya karşı direncinin yüksek olmas1, hücre çapının küçük olmasından kaynaklanabilir. Çünkü denklem 4'te verilen formül dikkate alındığında, hücre çap1 Şekil 5
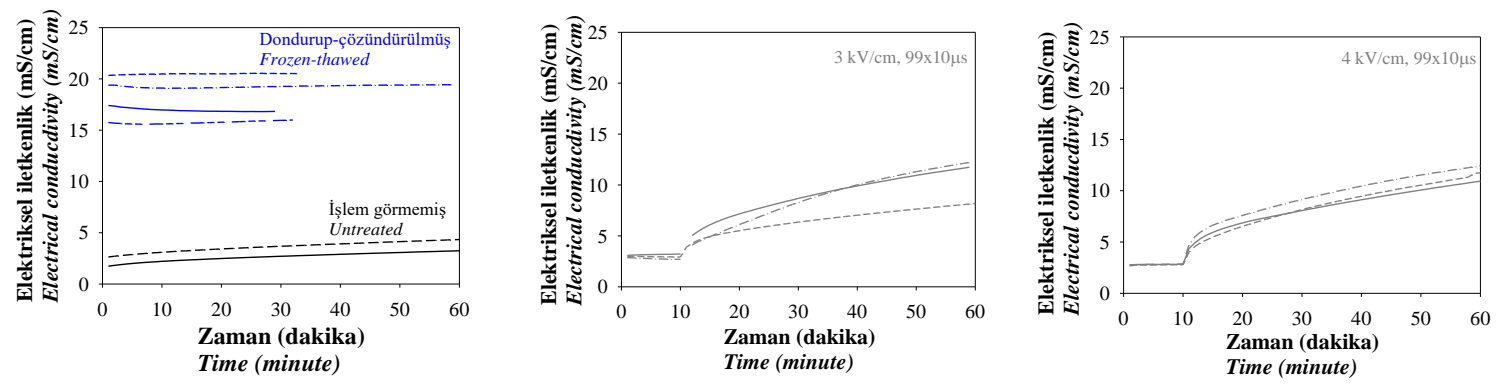

Şekil 4. İşlem görmemiş ve dondurulup çözülmüş (a) ve PEF uygulanmış dereotu örneklerinde elektriksel iletkenliğin zamana karşı değişimi (b, c)

Figure 4. Change in electrical conductivity versus time in untreated and frozen-thawed (a) and PEF-treated $(b, c)$ dill samples

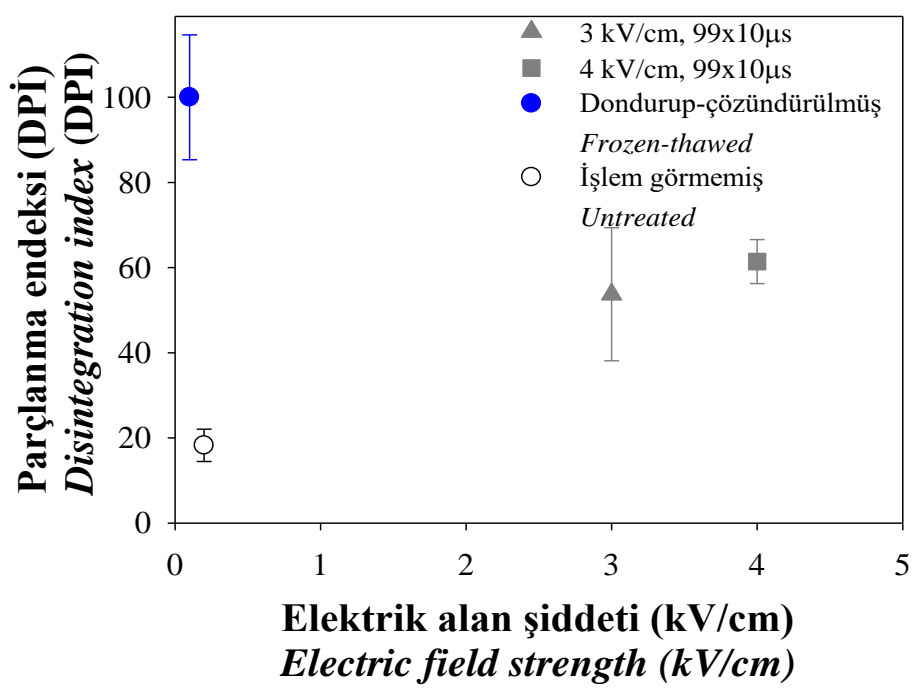

Şekil 5. Dereotu dokusuna 3 ve $4 \mathrm{kV} / \mathrm{cm}$ 'lik elektrik alan şiddetinde 99x10 $\mu$ s vurgu uygulanmas1 sonrasinda doku parçalanma indeksleri

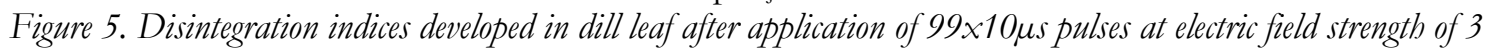
and $4 \mathrm{kV} / \mathrm{cm}$ 


\section{Fenolik maddelerin katı-sıvı} ekstraksiyonunda PEF'in etkileri

Şekil 6'de, PEF ve diğer ön işlemlere maruz birakılarak hücre parçalanması sağlanan örneklerin kat1-sıv1 ekstraksiyon işlemi sonras1 ölçülen toplam fenolik madde (TFI), antioksidan kapasite (AK) ve antiradikal aktivite (AA) analiz sonuçları gösterilmiştir. PEF uygulaması, yukarıda bahsedilen hücre içi iyonların salınımına sebebiyet verdiği gibi, hücrelerde bulunan fenolik maddelerin ekstraksiyonunda da ayn1 yolu izleyerek maddelerin ekstrakte edilebilirliğini sağlamıştır. PEF'in fenolik maddeleri ekstrakte etme etkinliği, dondurulup-çözündürme işlemi ile mukayese edilebilir bulunmuştur. Çizelge 1'de PEF ve dondurup-çözündürme işlemleri sonrası katı-sıvı ekstraksiyonunda, AK değerleri arasında istatiksel olarak önemli bir fark gözlenmezken (P $>0.05)$, PEF'in TFI ve AK değerleri, sirasiyla dondurup-çözündürülmüş örneklerin ortalamada $\% 60$ ve \% 78 'ini vermiştir. Doku parçalanma oranı dondurulup-çözündürme ön işleminde \%100'e yakın ve PEF ön işleminde bu oranın daha düşük

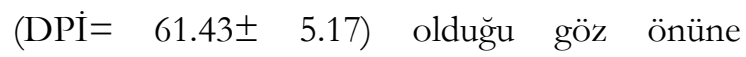
alındığında, doku parçalanma oranı ile fenolik maddelerin ekstraksiyon oranı arasında doğrusal bir ilişki görülmektedir. Bundan başka, ekstraksiyonda 1sıl işlem içeren ön işlemlerin (mikrodalga, 1sıl işlem ve solvent ekstraksiyonu) fenolik madde değerleri, 1sısal olmayan (PEF ve dondurup-çözündürme) işlemlerden genelde daha yüksek olduğu tespit edilmiştir. Ön işlemler arasında TFI değerleri kiyaslandığında, mikrodalga ön işlemi en yüksek değeri gösterirken, 1sıl işlem ve solvent ekstraksiyon ön işlemi birbirine yakın ( $\mathrm{P}>0.05)$ sonuçlar sergilemiştir. AK değerleri karşılaştırıldığında, solvent ekstraksiyon işlemi en yüksek değeri gösterirken, PEF işleminin ssıl işleme yakın (P $>0.05)$ ve mikrodalga ön işleminden daha düşük $(\mathrm{P}<0.05)$ değerler gösterdiği tespit edilmiştir. AA değerleri kıyaslandığında, ısıl işlem ve solvent ekstraksiyonu arasinda istatistiksel olarak belirgin bir fark gözlenmezken (P >0.05) solvent ekstraksiyon işlemi mikrodalga ön işleminden önemli derecede düşük bulunmuştur $(\mathrm{P}<0.05)$.

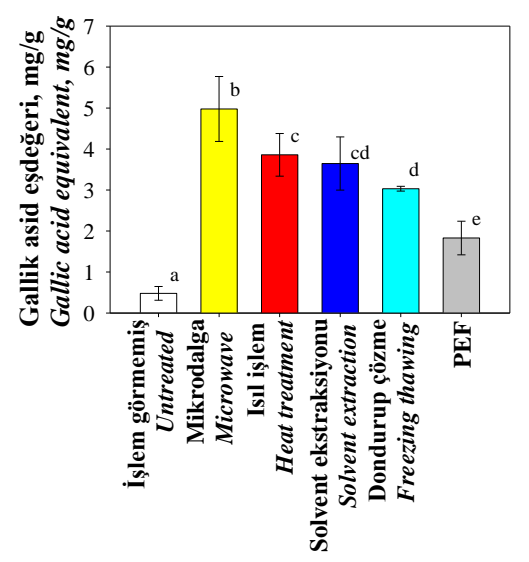

a)Toplam fenolik madde Total phenolic content

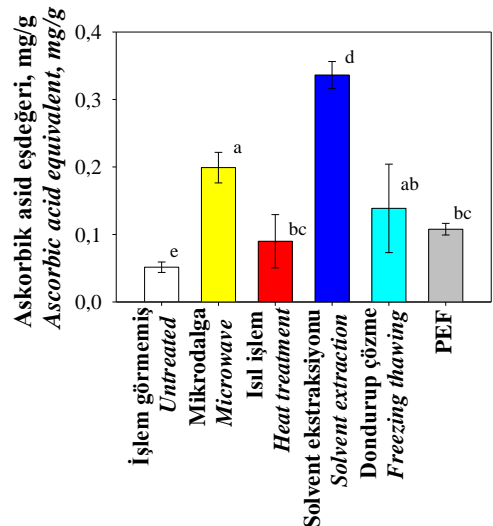

b) Antioksidan kapasite Antioxidant capacity

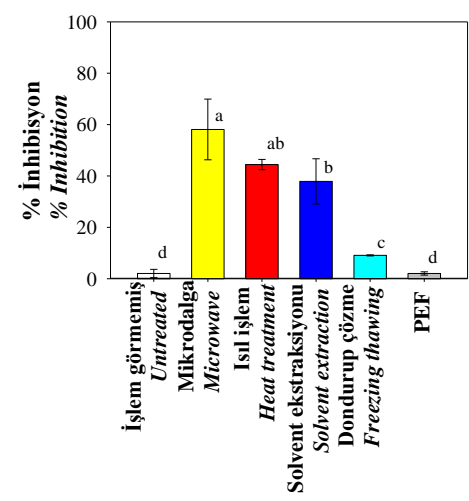

c) Antiradikal aktivite Antioxidant activity

Şekil 6. Taze dereotu dokusunun farklı yöntemlere parçalanıp katı-sıv1 ekstraksiyona maruz bırakılması sonrasinda ekstraktlarin toplam fenolik madde, antioksidan kapasite ve antiradikal aktivitesi. Her bir analiz kategorisinde aynı bir harfi paylaşmayan kolon simgeleri önişlemler arasında istatistiksel fark olduğunu ifade etmektedir $(\mathrm{P}<0.05)$

Figure 6. Total phenolic content, antioxidant capacity and antioxidant activity values of dill leaf disintegrated with different pretreatment methods, followed by solid-liquid extraction. In each category of analysis, column superscripts not sharing a letter means statistical difference between pretreatments $(P<0.05)$ 
Çizelge 1. Her bir ön işleme ait toplam fenolik madde (TF), antioksidan kapasite (AK) ve antiradikal aktivite (AA) değerleri

Table 1. Total phenolic content, antioxidant capacity and antioxidant activity values of dill leaf disintegrated with different pretreatment methods, followed by solid-liquid extraction.

\begin{tabular}{|c|c|c|c|}
\hline $\begin{array}{l}\text { Ön işlemler } \\
\text { Pre-treatments }\end{array}$ & $\begin{array}{l}\text { Toplam Fenolik } \\
\text { Madde } \\
\text { (mg gallik asit essd. } \\
\text { /g taze doku) } \\
\text { Total phenolic content } \\
\text { (mg gallic acid eqv. } / g \\
\text { fresh weight) }\end{array}$ & $\begin{array}{c}\text { Antioksidan Kapasite } \\
\text { (mg askorbik asit eşd. } \\
\text { /g taze doku) } \\
\text { Antioxidant capacity (mg } \\
\text { ascorbic acid eqv. } / g \text { fresh } \\
\text { weight) }\end{array}$ & $\begin{array}{c}\text { Antiradikal Aktivite } \\
\text { (\% İnhibisyon) } \\
\text { Antioxidant activity (\% } \\
\text { Inbibition) }\end{array}$ \\
\hline $\begin{array}{l}\text { Kontrol (İşlem görmemiş) } \\
\text { Control (Untreated) }\end{array}$ & $0.48 \pm 0.17$ a & $0.05 \pm 0.01$ a & $2.04 \pm 1.61^{\mathrm{d}}$ \\
\hline PEF & $1.83 \pm 0.41^{\mathrm{e}}$ & $0.11 \pm 0.01 \mathrm{bc}$ & $2.06 \pm 0.64^{\mathrm{d}}$ \\
\hline $\begin{array}{l}\text { Dondurup-çözündürme } \\
\text { Freezing-thawing }\end{array}$ & $3.03 \pm 0.06^{\mathrm{d}}$ & $0.14 \pm 0.06 \mathrm{ab}$ & $9.09 \pm 0.21^{c}$ \\
\hline $\begin{array}{l}\text { Mikrodalga } \\
\text { Microwave }\end{array}$ & $4.98 \pm 0.79 \mathrm{~b}$ & $0.20 \pm 0.02^{a}$ & $58.11 \pm 11.82^{a}$ \\
\hline $\begin{array}{l}\text { Issl işlem } \\
\text { Heat treatment }\end{array}$ & $3.86 \pm 0.52^{c}$ & $0.09 \pm 0.04^{\mathrm{bc}}$ & $44.44 \pm 2.01^{\mathrm{ab}}$ \\
\hline $\begin{array}{l}\text { Solvent ekstraksiyonu } \\
\text { Solvent extraction }\end{array}$ & $3.65 \pm 0.65^{\mathrm{cd}}$ & $0.34 \pm 0.20^{\mathrm{d}}$ & $37.90 \pm 8.79 \mathrm{~b}$ \\
\hline
\end{tabular}

Her bir sütunda aynı bir harfi paylaşmayan değerler, birbirinden istatiksel olarak farklı olduğunu ifade etmektedir $(\mathrm{P}<0.05)$. (In each category of analysis, column superscripts not sharing a letter means statistical difference between pretreatments $(P$ $<0.05)$ )

Isıl olmayan ön işlemler ile ekstrakte edilen fenolik madde değerlerinin isıl işlem içeren ön işlemlerden daha düşük olmasının enzim aktivitesi ile ilişkili olduğu düşünülmektedir. Gerek PEF uygulaması ve çözündürme esnasında gerekse 20 ${ }^{\circ}$ C'deki ekstraksiyon boyunca, aktif polifenol oksidaz enzimleri (PPO), fenolik maddeler üzerinde bozucu etki göstermesi mümkün olmaktadır. Isıl ön işlem içeren ekstraksiyonlardaki fenolik madde değerlerinin yüksekliği de bunu destekler niteliktedir. Zira PPO enzimlerinin 1sıl direnci düşük olup, inaktif olduklarında fenolik maddeler üzerinde bozucu etki gösteremezler (Pekyardımc1, 1992). Enzimler dışında, ısıl işlem de fenolik maddeler üzerinde etkide bulunmaktadır. Isının fenolik maddeler üzerinde etkisi, işlemin şiddeti (sıcaklık ve süre), fenolik madde çeşidi ve içinde bulunduğu ortamın özellikleri gibi unsurlara bağlı olarak değişebilmektedir. Birçok meyve ve sebzede ısının bozucu etkisi belirtilirken, bunun tam aksi yani 1sının fenolik madde değerlerini yükseltici etkisini rapor eden çalışmalar da vardır (Chipurura vd., 2010; Romero vd., 2014; Maghsoudlou vd., 2019; Radziejewska-Kubzdela vd., 2020). Isıl işlemin fenolik madde değerlerini yükseltici etkisi tam olarak açıklığa kavuşturulmamasına rağmen, isıl işlemin antioksidan özelliğe sahip yeni Maillard reaksiyon yan ürünlerinin oluşumuna ve hücre duvarını ileri derecede bozarak ekstraksiyonu artırabileceği öne sürülmüştür (Kaufmann ve Christen, 2002; Juániz vd., 2016; Kim vd., 2019)

Şekil 6'daki ekstraksiyon sonuçları bu açıdan değerlendirildiğinde, dereotundaki fenolik madde içeriği belirtilen 1sıl işlemlerde 1sısal olmayan işlemlere kıyasla daha fazla olduğu görülmektedir.

Bundan başka, Şekil 6'daki değerlerin ekstraksiyondaki çözünen ve çözgen (solvent) arasındaki polarite ilişkisinden etkilendiği düşünülmektedir. Ön işlemler sonrası 
gerçekleştirilen katı-sıvı ekstraksiyon deneylerinde, örnekler birçok açıldan benzer şartlara maruz bırakılmıştır ancak bununla birlikte ekstraksiyon sistemlerinde farklliklar da mevcuttur. Isıl işlem, mikrodalga, PEF, dondurup-çözündürme ön işlemi içeren ekstraksiyonlarda, çözgen madde polar ve izotoniktir (0.33 M mannitol çözeltisi) ve ekstraksiyon $20^{\circ} \mathrm{C}$ 'de gerçekleştirilmiştir. Solvent ekstraksiyon sisteminde ise fenolik maddelerin daha fazla çözünmesine elverecek polar protik çözgen (20: 80, su / etanol) kullanılmış, önemli bir fark olarak ekstraksiyon $70 \quad{ }^{\circ} C^{\prime}$ de gerçekleştirilmiştir. Şekil 6c'de en yüksek $\mathrm{AK}$ değeri, solvent ekstraksiyon ön işleminde bulunmuştur.

Ekstraksiyon verimini etkileyen diğer bir unsur, ön işlemlerin dokuyu hangi oranda parçaladığ veya hücre zarını hangi oranda bozduğudur. Bu anlamda, özellikle taze dokuları parçalama yöntemlerinde uygulanan sıcaklık derecesi önemli olmaktadır. Isıl yöntem ile gerçekleşen parçalama metotlarında, parçalanma mekanizması çoğunlukla hücre zarlarının erimesi ile olmaktadır. Buna örnek olarak Eshtiaghi ve Knorr (2002) yaptığı çalışma incelendiğinde, belirli bir sıcaklık derecesi üzerinde şeker pancarı dokusunun hücre zarının 1sı etkisiyle bozunduğu gözlenmiştir. PEF işlemi hariç deneylerde kullanılan diğer ön işlemlerde, işlemler \%100 hücre parçalanmasına yakın olacak şekilde tasarlanmıştır. Ancak PEF ön işleminde en fazla \%61.43 \pm 5.17 oranında hücre parçalanması gerçekleşmiştir. Solvent ekstraksiyon işleminde hücre parçalanması ve ekstraksiyon aynı esnada gerçekleşirken, diğer bütün ekstraksiyon sistemlerinde hücre parçalanması ekstraksiyon öncesinde sağlanmıştır.

\section{SONUÇ}

Yapılan bu çalışma, yapraksı dokuların PEF ile parçalanabileceğini, ayrıca PEF ile parçalanmış dokuların katı-sıvı ekstraksiyon işlemine maruz bırakıldığında, fenolik maddelerin ekstrakte edilebileceğini göstermiştir. Uygulanan elektriksel parametrelere ve dokuların muamele edildiği ortamın özelliklerine göre kısmi değişiklikler gösterebilmesine rağmen, birçok meyve dokusu genellikle 1- $2 \mathrm{kV} / \mathrm{cm}$ 'de bütüne yakın parçalanmaktadır. Bu çalışmada dereotu dokusun PEF ile parçalanmaya karşı gösterdiği direncin nane gibi diğer benzer bir bitki dokusundan daha yüksek olduğuna ve bütüne yakın parçalanmasının sağlanması için $4 \mathrm{kV} / \mathrm{cm}$ üzerinde bir elektrik alan kuvveti kullanımı gerektiğine işaret edilmiştir (Fincan, 2015). Ayrica PEF'in fenolik maddeleri ekstrakte etme davranışının, dondurupçözündürme işlemine benzediği belirtilmiştir.

Bu çalışmada, fenolik maddelere dair ekstraksiyon verimini belirlemede Folin-Ciocalteu, phosphomolybdenum ve DPPH metotlarından elde edilen sonuçlar arasında her zaman paralellik bulunmamıştır. PEF'in fenolik madde ekstraksiyonundaki etkinliği, genellikle dondurupçözündürme işleminin etkinliğine benzemektedir. Ancak toplam fenolik içerik değerinde, dondurup çözündürme işleminin etkinliği, PEF işleminden daha düşüktür. Dondurup-çözünmüş örneklerde, çözündürme sırasında bekleme süresi göz önüne alındığında, fenolik maddelerin enzimlerce parçalanması söz konusu olmaktadır. Isıl işlem içeren örneklerde fenolik madde analizlerinin genellikle yüksek çıkması, enzimlerin ekstraksiyondaki etkisini destekler niteliktedir. Çünkü 1sıl işlemde enzimlerin inaktivasyonu söz konusu olmaktadır. Bundan başka, 1sıl işlemin fenolik maddeler üzerinde etkisi, bitkiye özgü fenolik madde çeşidine göre değiştiği ve bazı çalışmalarda artış, bazılarında ise azalmaya yol açtı̆̆ bildirilmektedir. Yapılan bu çalışmada, dereotu örneklerinin PEF ile fenolik madde ekstraksiyonunun diğer işlemlere kıyasla daha az miktarda sonuçlandığı denemelerde gösterilmiş ve bunun PEF ile muamele edilmiş örneklerde doku bozunum oranının \%100' e yakın olmaması ve ekstraksiyon süresince aktif kalan PPO gibi enzimlerin fenolik maddeleri bozma etkilerinden kaynaklanabileceğine işaret edilmiştir.

\section{ÇIKAR ÇATIŞMASI BEYANI}

Yazarlar arasında çıkar çatışması bulunmamaktadır.

\section{YAZAR KATKILARI}

Tüm yazarlar makalenin oluşumundaki farklı süreçlerde önemli derecede katkı sağlamışlardır. 
Mustafa Fincan makalenin son halini okudu ve onaylad1.

\section{TEŞEKKÜR}

$\mathrm{Bu}$ çalışma Türkiye Bilimsel ve Teknolojik Araştırma Kurumu, TUBİTAK, tarafindan 108 O 641 proje kodu ile desteklenmiştir.

\section{KAYNAKLAR}

Ade-Omowaye, B. I. O., Angersbach, A., Eshtiaghi, N. M., Knorr, D. (2000). Impact of High Intensity Electric Field Pulses on Cell Permeabilisation and as Pre-Processing Step in Coconut Processing. Innov Food Sci Emerg Technol, 1(3), 203-209. https://doi.org/10.1016/S14668564(00)00014-X

Angersbach, A., Heinz, V., Knorr, D. (2002). Evaluation of Process-Induced Dimensional Changes in the Membrane Structure of Biological Cells Using Impedance Measurement. Biotechnol Prog, 18(3), 597-603. https://doi.org/10.1021/ bp020047j

Barba, F. J., Jäger, H., Meneses, N., Esteve, M. J., Frígola, A., Knorr, D. (2012). Evaluation of Quality Changes of Blueberry Juice During Refrigerated Storage After High-Pressure and Pulsed Electric Fields Processing. Innov Food Sci Emerg Technol, 14, 18-24. https://doi.org/ 10.1016/j.ifset.2011.12.004

Barsotti, I., Cheftel, J. C. (1999). Food Processing by Pulsed Electric Fields. II. Biological Aspects. Food Rev Int, 15(2), 181-213. https://doi.org/ 10.1080/87559129909541186

Bazhal, M., Nikolai, L., Vorobiev, E., (2003). Optimisation of Pulsed Electric Field Strength for Electroplasmolysis of Vegetable Tissues. Biosyst Eng, 86(3), 339-345. https://doi.org/10.1016/ S1537-5110(03)00139-9

Chipurura, B., Muchuweti, M., Manditseraa, F. (2010). Effects of Thermal Treatment on the Phenolic Content and Antioxidant Activity of Some Vegetables. Asian J Clin Nutr, 2(3), 93-100. https://doi.org/10.3923/ajcn.2010.93.100

Chumyam, A., Whangchai, K., Jungklang, J., Faiyue, B. (2013). Effects of Heat Treatments on Antioxidant Capacity and Total Phenolic Content of Four Cultivars of Purple Skin Eggplants. ScienceAsia, 39(3), 246-251. https://doi.org /10.2306/scienceasia1513-1874.2013.39.246

Xu, C., Wang, B., Pu, Y., Tao, J., Zhang, T. (2017). Advances in Extraction and Analysis of Phenolic Compounds from Plant Materials. Chin J Nat Med, 15(10), 721-731. https://doi.org/10.1016/ S1875-5364(17)30103-6

Dai, J., Mumper, R. J. (2010). Plant Phenolics: Extraction, Analysis and Their Antioxidant and Anticancer Properties. Molecules, 15(10), 73137352. https://doi.org/10.3390/ molecules15107313.

Dhiman, C., Kumar, N., Kothiyal, P. (2017). Pharmacological Actions of Anethum graveolens (Dill). J Phar Res, 11(5), 511-516.

Eshtiaghi, M. N., Knorr, D. (2002). High Electric Field Pulse Pretreatment: Potential for Sugar Beet Processing. J Food Eng, 52(3), 265-272. https://doi.org/10.1016/S0260-8774(01)001145

Fanasca, S., Rouphael, Y., Venneria, E., Azzini, E., Durazzo, A., Maiani, G. (2009). Antioxidant Properties of Raw and Cooked Spears of Green Asparagus Cultivars. Int J Food Sci Technol, 44, 1017-1023. https://doi.org/10.1111/j.13652621.2008.01871.x

Fincan, M. (2015). Extractability of Phenolics from Spearmint Treated with Pulsed Electric Field. J Food Eng, 162, 31-37. https://doi.org/10.1016/j.jfoodeng.2015.04.004

Fincan, M., Dejmek, P. (2002). In Situ Visualization of the Effect of a Pulsed Electric Field on Plant Tissue. J Food Eng, 55(3), 223-230. https://doi.org/10.1016/S0260-8774(02)000791

Donsì, F., Ferrari, G., Pataro, G. (2010). Applications of Pulsed Electric Field Treatments for the Enhancement of Mass Transfer from Vegetable Tissue. Food Eng Rev, 2(2), 109-130.

Gachovska, T., Cassada, D., Subbiah, J., Hanna, M., Thippareddi, H., Snow, D. (2010). Enhanced Anthocyanin Extraction from Red Cabbage Using Pulsed Electric Field Processing, J Food Sci, 
75(6), 323-329. https://doi.org/10.1111/j.17503841.2010.01699.x.

Gaidamauskas, E., Norkus, E., Vaičiūnienè, J., Crans, D. C., Vuorinen, T., Jačiauskienė, J., Baltrūnas, G. (2005). Evidence of Two-step Deprotonation of D-mannitol in Aqueous Solution. Carbohyd Res, 340(8), 1553-1556. https://doi.org/10.1016/j.carres.2005.03.006

Niya, M. H., Aryai, P., Fatahi, E. (2016). The Effect of Extraction Methods on Phenolic and Tocophorol Content and Antioxidant Properties of Dill Extracts (Anethum Graveolens). Iranian J Food Sci Technol, 13(57), 109-119.

Isbilir, S. S., Sagiroglu, A. (2011). Antioxidant Poteniral of Different Dill (Anethum Graveolens L.) Leaf Extracts. Int J Food Prop, 14(4), 894-902. https://doi.org/10.1080/10942910903474401

Jana, S., Shekhawat, G. S. (2010). Anethum graveolens: An Indian Traditional Medicinal Herb and Spice. Pharmacogn Rev, 4(8), 179-184. https://doi.org/10.4103/0973-7847.70915

Kaufmann, B., Christen, P. (2002). Recent Extraction Techniques for Natural Products: Microwave-assisted Extraction and Pressurised Solvent Extraction. Phytochem Anal, 13(2), 105113. https://doi.org/10.1002/pca.631

Kunyanga, C. N., Imungi, J. K., Okoth, M. W., Biesalski, H. K., Vadivel, V. (2012). Total Phenolic Content, Antioxidant and Antidiabetic Properties of Methanolic Extract of Raw and Traditionally Processed Kenyan İndigenous Food İngredients. LWT- Food Sci Technol, 45(2), 269276. https://doi.org/10.1016/j.lwt.2011.08.006

Liu, Z., Esveld, E., Vincken, J., Bruins, M. E. (2019). Pulsed Electric Field as an Alternative Pretreatment for Drying to Enhance Polyphenol Extraction from Fresh Tea Leaves, Food Bioproc Technol, 12, 183-192. https://doi.org/10.1007/ s11947-018-2199-x

Maghsoudlou, Y., Ghajari, M. A., Tavasoli, S. (2019). Effects of Heat Treatment on the Phenolic Compounds and Antioxidant Capacity of Quince Fruit and Its Tisane's Sensory Properties. J Food Sci Technol, 56(5), 2365-2372. https://doi.org/10.1007/s13197-019-03644-6
Nguyen, V. T., Nguyen, N. Q., An, T. N. T., Van, N. T., Anh, N. H. T. (2020). Evaluation of Polyphenol Content and Antioxidant Activities of Dill Leaves Extract Anethum graveolens L., IOP Conf Ser: Mater Sci Eng, 991, 012032. https://doi.org/10.1088/1757-

899X/991/1/012032

Pan, X., Niu, G., Liu, H. (2003). Microwaveassisted Extraction of Tea Polyphenols and Tea Caffeine from Green Tea Leaves. Chem Eng Process, 42(2), 129-133. https://doi.org/10.1016/ S0255-2701(02)00037-5

Pandey, M. M., Vijayakumar, M., Rastogi, S., Rawat, A. K. S. (2013). Phenolic Content and Antioxidant Properties of Selected Indian Spices of Apiaceae Phenolic Content and Antioxidant Properties of Selected Indian Spices of Apiaceae. J Herbs Spices Med Plants, 18(3), 246-256. https://doi.org/10.1080/10496475.2012.680548

Paven, C. S. J., Radu, D., Alexa, E., Pintilie, S., Rivis, A. (2018). Anethum graveolens- An Important Source of Antioxidant Compounds for Food Industry. 18th International Multidisciplinary Scientific GeoConferance, 02-08 July 2018, Sofia, Bulgaria, pp.11-18. https://doi.org/10.5593/ sgem2018/6.2/S25.002

Pekyardımcı, Ş. (1992). Polifenol Oksidaz Enzimi ve Esmerleşme Reaksiyonlarının Gıda Endüstrisi Uygulamalar1. Gida, 17(3), 181-186. https://dergipark.org.tr/tr/pub/gida/issue/695 3/92734

Cao, S., Wan, C., Yu, Y., Zhou, S., Liu, W., Tian, S. (2011). Antioxidant Activity and Free RadicalScavenging Capacity of Gynura Divaricata Leaf Extracts at Different Temperatures. Pharmacogn Mag, 7(25), 40. https://doi.org/10.4103/09731296.75900

Radziejewska-Kubzdela, E., Szwengiel, A., Ratajkiewicz, H., Nowak, K. (2020). Effect of Ultrasound, Heating and Enzymatic PreTreatment on Bioactive Compounds in Juice from Berberis amurensis Rupr. Ultrason Sonochem, 63, 104971. https://doi.org/10.1016/ j.ultsonch.2020.104971

Romero, J. F., Díaz-moreno, C., Bernal-Roa, L. J. (2014). Influencia de Tratamientos Térmicos 
sobre la Capacidad Antioxidante de Espinaca (Spinacea oleracea L.). Acta Hortic, 1016, 109-112. https://doi.org/10.17660/ActaHortic.2014.1016 .13

De Vito, F., Ferrari, G., Lebovka, N. I., Shynkaryk, N. V., Vorobiev, E. (2008). Pulse Duration and Efficiency of Soft Cellular Tissue Disintegration by Pulsed Electric Fields. Food Bioproc Tech, 1(4), 307-313. https://doi.org/ 10.1007/s11947-007-0017-y

Roy, M. K., Takenaka, M., Isobe, S., Tsushida, T. (2007). Antioxidant Potential, Anti-Proliferative Activities, and Phenolic Content in Water-Soluble Fractions of Some Commonly Consumed Vegetables: Effects of Thermal Treatment. Food Chem, 103(1), 106-114. https://doi.org/10.1016/ j.foodchem.2006.08.002

Sánchez-Moreno, C., Larrauri, J. A., Saura-calixto, F. (1998). A Procedure to Measure the Antiradical Efficiency of Polyphenols. J Sci Food Agric, 76, 270-276. https://doi.org/10.1002/(SICI)10970010(199802) 76:2<270::AID-

JSFA945>3.0.CO;2-9

Saulis, G. (2010). Electroporation of Cell Membranes: The Fundamental Effects of Pulsed Electric Fields in Food Processing. Food Eng Rev, 2(2), 52-73. https://doi.org/10.1007/s12393010-9023-3

Shyu, Y., Lin, J., Chang, Y., Chiang, C., Yang, D. (2009). Evaluation of Antioxidant Ability of Ethanolic Extract from Dill (Anethum graveolens L.) Flower. Food Chem, 115(2), 515-521. https://doi.org/10.1016/j.foodchem.2008.12.03 9

Carbonell-Capella, J. M., Brnčić, S. R., Žlabur, J. Š., Barba, F. J., Grimi, N., Koubaa, M., Brnčić, M., Vorobiev, E. (2017). Electrotechnologies, Microwaves, and Ultrasounds Combined with Binary Mixtures of Ethanol and Water to Extract Steviol Glycosides and Antioxidant Compounds from Stevia rebaudiana Leaves, J Food Process Preserv, 41(5), 1-9. https://doi.org/10.1111/jfpp.13179

Soliva-Fortuny, R., Balasa, A., Knorr, D., MartínBelloso, O. (2009). Effects of Pulsed Electric Fields on Bioactive Compounds in Foods: A
Review. Trends Food Sci Technol, 20(11-12), 544 556. https://doi.org/10.1016/j.tifs.2009.07.003

Świeca, M., Gawlik-Dziki, U. (2008). Influence of Thermal Processing on Phenolics Compounds Level and Antiradical Activity of Dill (Anethum graveolens L.). Herba Pol, 54(3), 59-69.

Vallverdú-Queralt, A., Regueiro, J., Alvarenga, J. F. R., Martínez-Huélamo, M., Leal, L. N., Lamuela-Raventós, R. M. L. (2015). Characterization of the Phenolic and Antioxidant Profiles of Selected Culinary Herbs and Spices: Caraway, Turmeric, Dill, Marjoram and Nutmeg. J Food Sci Tecbnol, 35(1), 189-195. https://doi.org/10.1590/1678-457X.6580

Vallverdu-Queralt, A., Oms-Oliu, G., OdriozolaSerrano, I., Lamuela-Raventos, R. M., MartínBelloso, O., Elez-Martínez, P. (2012). Effects of Pulsed Electric Fields on the Bioactive Compound Content, J Agric Food Chem, 60(12), 3126-3134. https://doi.org/10.1021/jf205216m

Nagy, M., Tofană, M., Socaci, S. A., Pop, A. V., Borş, M. D., Fărcaş, A., Moldovan, O. (2014). Total Phenolic, Flavonoids and Antioxidant Capacity of Some Medicinal and Aromatic Plants. Bulletin of University of Agricultural Sciences and Veterinary Medicine Cluj-Napoca. Food Sci Technol, 71(2). https://doi.org/10.15835/buasvmcnfst:10639

Wilson, L. (2016). Spices and Flavoring Crops: Fruits and Seeds, Encyclopedia of Food and Health. In: Encyclopedia of Food and Health (1st ed.), Caballero, B., Finglas, P., Toldrá, F., (Eds.), Academic Press. pp.73-83

Zhang, M. I. N., Willison, J. H. M. (1992). Electrical Impedance Analysis in Plant Tissues: The Effect of Freeze-Thaw Injury on the Electrical Properties of Potato Tuber and Carrot Root Tissues. Can J Plant Sci, 72(2), 545-553. https://doi.org/10.4141/cjps92-068

Handa, S. S., Khanuja, S. P. S., Longo, G., Rakesh, D.D. (2008). Extraction Techniques for Medicinal and Aromatic Plants. (1st ed.), United Nations Industrial Development Organization and the International Centre for Science and High Technology, Trieste, Italy, pp. 21-52. 
Kim, M. Y., Lee, B. W., Lee, H. U., Lee, Y. Y., Kim, M. H., Lee, J. Y., Lee B. K., Woo, K. S., Kim, H. J. (2019). Phenolic Compounds and Antioxidant Activity in Sweet Potato After Heat Treatment. J Sci Food Agric, 99(15), 6833-6840. https://doi.org/10.1002/jsfa.9968

Juániz, I., Ludwig, I. A., Huarte, E., Pereira-Caro, G., Moreno-Rojas, J. M., Cid, C., De Peña, M. P. (2016). Influence of Heat Treatment on Antioxidant Capacity and (Poly) Phenolic Compounds of Selected Vegetables. Food Chem,
197, 466-473. https://doi.org/10.1016/ j.foodchem.2015.10.139

Turkmen, N., Sari, F., Velioglu, Y. S. (2005). The Effect of Cooking Methods on Total Phenolics and Antioxidant Activity of Selected Green Vegetables. Food Chem, 93(4), 713-718. https://doi.org/10.1016/j.foodchem.2004.12.03 8 